\title{
Laparoscopy Guided Doppler Ultrasound Measurement of Fetal Blood Flow Indices During Early to Mid-Gestation in Pigs
}

\author{
Klaus-Peter BRÜSSOW'1), Jürgen KURTH'1), Andreas VERNUNFT'1), Frank BECKER ${ }^{1)}$, \\ Armin TUCHSCHERER ${ }^{1)}$ and Wilhelm KANITZ1)
}

\author{
1) Leibniz Institute for Farm Animal Biology (FBN), D-18196 Dummerstorf, Germany
}

\begin{abstract}
The objectives of this study were to obtain relevant blood flow indices of umbilical arteries (UmA) of porcine fetuses using a laparoscopic ultrasound probe and to relate these data with fetal size at early to mid gestation. Fetal parameters and flow indices, i.e., fetal length and area, fetal heart rate (FHR), systolic pulse duration (T1), interpulse duration (T2), T2/T1 ratio, peak systolic velocity (PSV), time averaged velocity (TAV), resistance index (RI) and pulsatility index (PI), were measured in 182 fetuses of 26 pregnant Landrace gilts on pregnancy day (PD) 36 (122 fetuses from 17 gilts), PD42 (19 fetuses from 3 gilts) and PD51 (42 fetuses from 6 gilts). Fetal heart rate was higher on PD36 than on PD42 ( $\mathrm{P}<0.05)$. No differences $(\mathrm{P}>0.05)$ were obtained concerning systolic pulse duration, flow velocities and RI. On $\mathrm{PD} 42$, the $\mathrm{PI}$ was lower $(\mathrm{P}<0.05)$, while the interpulse duration $(\mathrm{P}=0.06)$ and $\mathrm{T} 2 / \mathrm{T} 1$ ratio tended $(\mathrm{P}=0.08)$ to be higher on PD42 compared with PD36 and to PD51. To find differences in UmA blood flow parameters concerning fetal size, i.e., fetal length, fetuses were retrospectively grouped as follows: small (lower 25\%), medium (mean 50\%) and large (upper $25 \%)$, respectively. Although, fetuses differed in size $(\mathrm{P}<0.001)$ within and between days of pregnancy, FHR, PSV, TAV, RI and PI did not differ $(\mathrm{P}>0.05)$ among the size classes. Only systolic pulse duration tended to be longer $(\mathrm{P}=0.05)$ in large compared with small fetuses on PD36, and interpulse duration was lower in large fetuses on PD36 in comparison with PD51 $(\mathrm{P}<0.05)$. Though there was no link between fetal blood flow indices and fetal intrauterine growth retardation (IUGR), with further studies based on these flow indices, it might be possible to evaluate nutrient- or stress-related influences on fetal growth and development, particularly in the case of IUGR.
\end{abstract}

Key words: Female pig, Fetal blood flow, Laparoscopy, Pregnancy, Ultrasonography

(J. Reprod. Dev. 58: 243-247, 2012)

$\mathbf{T}$ he profitability of pig production considerably depends on the number of live born and fostered piglets. Breeding efforts result nowadays in a greater than before number of piglets. However, pre- and postnatal losses are concomitantly increasing (up to $30 \%$ ) [1]. Furthermore, intrauterine growth retardation (IUGR), resulting in lighter body weight at birth, is a significant problem in pig production [2]. Lighter birth weight piglets show reduced survival rate, compromised postnatal development [3] as well as decreased carcass and meat quality [4]. Uterine and umbilical blood flows maintain the placental transport and exchange of respiratory gases, nutrients and wastes, and thereby support fetal growth and metabolism [5]. As previously demonstrated in the pig, the blood flow to the fetus was reduced with increasing number of fetuses [6]. Experimental vascular occlusion of the uterine arteries of pigs markedly reduced conceptus development [7]. In utero growth retardation, beside other factors such as uterine capacity and number and position of fetuses in the uterus, is mainly caused by limited oxygen and nutrient supply via the placenta [8]. Therefore, fetal blood supply could be worth analyzing to investigate fetal nutrition and growth, especially in IUGR piglets. Previously, uterine blood

Received: May 9, 2011

Accepted: December 13, 2011

Published online in J-STAGE: January 6, 2012

(C)2012 by the Society for Reproduction and Development

Correspondence: K-P Brüssow (e-mail: bruessow@fbn-dummerstorf.de) flow has been measured in pigs during pregnancy by electromagnetic flow transducers [9] and ultrasonic transit time flow probes [10].

Noninvasive techniques of Doppler blood flow measurements have been established in human obstetric practice to access fetoplacental and uteroplacental circulation, especially to predict fetal intrauterine growth restriction [11-15]. It was demonstrated that reduced blood flow in the umbilical vessels of human fetuses was related to fetal growth retardation $[16,17]$. In farm animals, ultrasound blood flow measurement in uterine and fetal vessels has been performed to a lower extent in cattle [18], horses [19], sheep [20-22] and goats [23]. Currently, relevant data are missing in the pig. Transabdominal measurement of umbilical blood flow is nearly impossible in pigs due to the high number of fetuses and their crowded location within the uterus. Hence, laparoscopy guided Doppler measurement is a feasible alternative.

The aim of the current study was to obtain relevant fetal umbilical blood flow indices using a laparoscopic ultrasound probe and to relate these data with fetal size at early mid-gestation.

\section{Materials and Methods}

\section{Animals and animal treatment}

All procedures involving animal handling and treatment were approved by the Committee for Animal Use and Care of the Agricultural Ministerial Department of Mecklenburg-Vorpommern, Germany (approval: LALLF-MV/TSD/7221.3-1.1-061/06). Altogether, 26 
pregnant Landrace gilts (10.5 month, with $156 \pm 4 \mathrm{~kg}$ body weight) were included in the trial. Estrus was synchronized in all gilts by 15 days of feeding with Regumate ${ }^{\circledR}$ (16 mg altrenogest/day/ gilt; Janssen-Cilag GmbH, Neuss, Germany). Twenty-four hours after the last Regumate ${ }^{\circledR}$ feeding $(0800$ h), each animal received a single intramuscular injection of 850 IU equine chorionic gonadotropin (eCG; Pregmagon ${ }^{\circ}$, IDT Biologika, Dessau-Tornau, Germany). Ovulation was induced $80 \mathrm{~h}$ later by administration of 500 IU human chorionic gonadotropin (hCG; Ovogest ${ }^{\circledR}$, Intervet, Unterschleißheim, Germany). All gilts were fixed-time inseminated $24 \mathrm{~h}$ and $38 \mathrm{~h}$ after administration of hCG. The day of the $2^{\text {nd }}$ insemination corresponded to Day 1 of pregnancy (PD1).

Gilts were slaughtered 9 to 10 days after the ultrasound measurement to record the total number of fetuses.

\section{Laparoscopic procedures and Doppler ultrasound measurements}

Laparoscopy guided Doppler ultrasonography was performed altogether on 183 fetuses at PD36 (122 fetuses from 17 gilts), PD42 (19 fetuses from 3 gilts) and PD51 (42 fetuses from 6 gilts), respectively. Laparoscopy was performed as previously described [24]. Briefly, anaesthetized gilts (ketamine, $0.15 \mathrm{ml} / \mathrm{kg} \mathrm{BW}$ Ursotamin, Serumwerk Bernburg, Germany; azaperone, 0.04 ml/kg BW Stresnil, Janssen Cilag GmbH, Neuss, Germany) were fixed in a dorsal position. A pneumoperitoneum was automatically produced with $\mathrm{CO}_{2}$ (Endo Tech, Munich, Germany). Thereafter, four trocar cannulas (Storz, Tuttlingen, Germany) were inserted into the abdomen for $0^{\circ}$ optics (ETB, Berlin, Germany), the laparoscopic ultrasound probe (EUP-OL531, Hitachi Medical Corporation, Tokyo, Japan) and grasping forceps (ErgoLAP, Bowa-electronic, Gomaringen, Germany). All laparoscopic handling was monitored on a video system (Endo Tech, Munich, Germany).

Each time, the first fetus of the left uterine horn was located next to the bifurcation, and the uterine horn was gently fixed by atraumatic forceps. The tip of the $7.5 \mathrm{MHz}$ ultrasound probe was placed directly on the uterine surface next to the fetus and a B-mode image was recorded to the hard disc of the ultrasound scanner equipment (EUB-6500, Hitachi Medical, Tokyo, Japan) for subsequent measurement of fetal size. Umbilical arteries (UmA) in a midcord site of the free-floating umbilical cord were visualized by color Doppler, and then pulsed wave Doppler was applied to record the waveforms with at least three consecutive cardiac cycles [25]. Thereafter, the measurement was continued with the laterally located fetus. Thereby, we aimed to analyze the total number of fetuses from one uterine horn or at least three fetuses.

Recorded images were analyzed later. Fetal size was measured in length and width, and the UmA waveform envelope curves were traced. The following parameters were calculated automatically by the integrated software package: fetal area $\left(\mathrm{FA}, \mathrm{cm}^{2}\right)$, fetal heart rate (FHR, bpm), systolic pulse duration (T1, ms), interpulse duration (T2, ms), T2/T1 ratio (\%), peak systolic velocity (PSV, cm/ $\mathrm{sec})$ and time averaged velocity $(\mathrm{TAV}, \mathrm{cm} / \mathrm{sec})$, resistance index (RI) and pulsatility index (PI), respectively.

\section{Statistical analysis}

The statistical analyses were performed using SAS software (SAS
Institute, Cary, NC, USA). Fetal and umbilical blood flow parameters of fetuses were tested for normality (UNIVARIATE procedure in the Base SAS software) [26]. Investigated parameters were approximately normal and could be evaluated by repeated measures analysis of variance (ANOVA) using the MIXED procedure of SAS/ STAT software [27]. The mixed model for the response variables fetus area (FA), fetal heart rate (FHR), systolic pulse duration (T1), interpulse duration (T2), T2/T1-ratio, peak systolic velocity (PSV), time averaged velocity (TAV), resistance index (RI) and pulsatility index (PI) contained the fixed effects day of pregnancy (levels: PD36, PD42, PD51) and fetal size group (levels: small, medium, large size), their interaction and a random gilt effect. Measures on fetuses of the same gilt are not independent. This dependence (sibs) can be modeled by considering measures on fetuses of the same gilt as repeated measures (repeated statement in PROC MIXED) using a compound symmetry block diagonal structure of the residual covariance matrix, where the blocks represent the gilts and the dimensions of the blocks represents the number of their fetuses. The model for the response variable fetus length (FL) included the fixed effect day of pregnancy (levels: PD36, PD42, PD51) and a random gilt effect. Measures on fetuses of the same gilt were considered as repeated measures and handled in the same way as described above. In addition, LS Means and their standard errors (SE) were calculated and pairwise tested for each effect in each model using the Tukey procedure for pairwise multiple comparisons.

Correlations were calculated between fetal size (FA, FL) and UmA flow parameters (FHR, T1, T2, T2/T1-ratio, PSV, TAV, RI, PI) using the CORR procedure of the Base SAS software [26] for each PD.

Test results with $\mathrm{P}$ values less than 0.05 are considered to be significant, and $\mathrm{P}$ values between 0.05 and 0.1 are defined as indicating tendency.

\section{Results}

The examination generally lasted between 45 and 90 min depending on the number of recorded fetuses. Handling and measurements with the EUP-OL531 laparoscopic ultrasound probe could be performed without difficulties on PD36. However, with ongoing gestation (PD42 and PD51) and in the case of a high number of fetuses and due to limited space, it becomes more difficult to handle the uterus intra-abdominally with the laparoscopic instruments and to keep records. However, after the umbilical cord was visualized, the flow velocity waveforms could be obtained without serious problems. Figure 1 shows a typical laparoscopic ultrasound image.

Altogether, 144 and 38 fetuses of the left and of right uterine horns, respectively, were ultrasonographically evaluated. This represents $94 \%$ of the fetuses in the left uterine horn and $32 \%$ of those in the right horn. The maximum and minimum numbers of fetuses analyzed per gilt were 13 and 3 on PD36, 6 and 6 on PD42, and 14 and 4 on PD51, respectively.

Fetal size and UmA blood flow parameters on PD36, PD42 and PD51 are presented in Table1. Fetal length and area increased $(\mathrm{P}<0.001)$ with ongoing gestation. Fetal heart rate was different on PD36 and PD41 $(\mathrm{P}<0.05)$. No differences were obtained concerning systolic pulse duration, flow velocities and RI. The PI was lower $(\mathrm{P}<0.05)$, and interpulse duration $(\mathrm{P}=0.06)$ and $\mathrm{T} 2 / \mathrm{T} 1$ ratio tended 


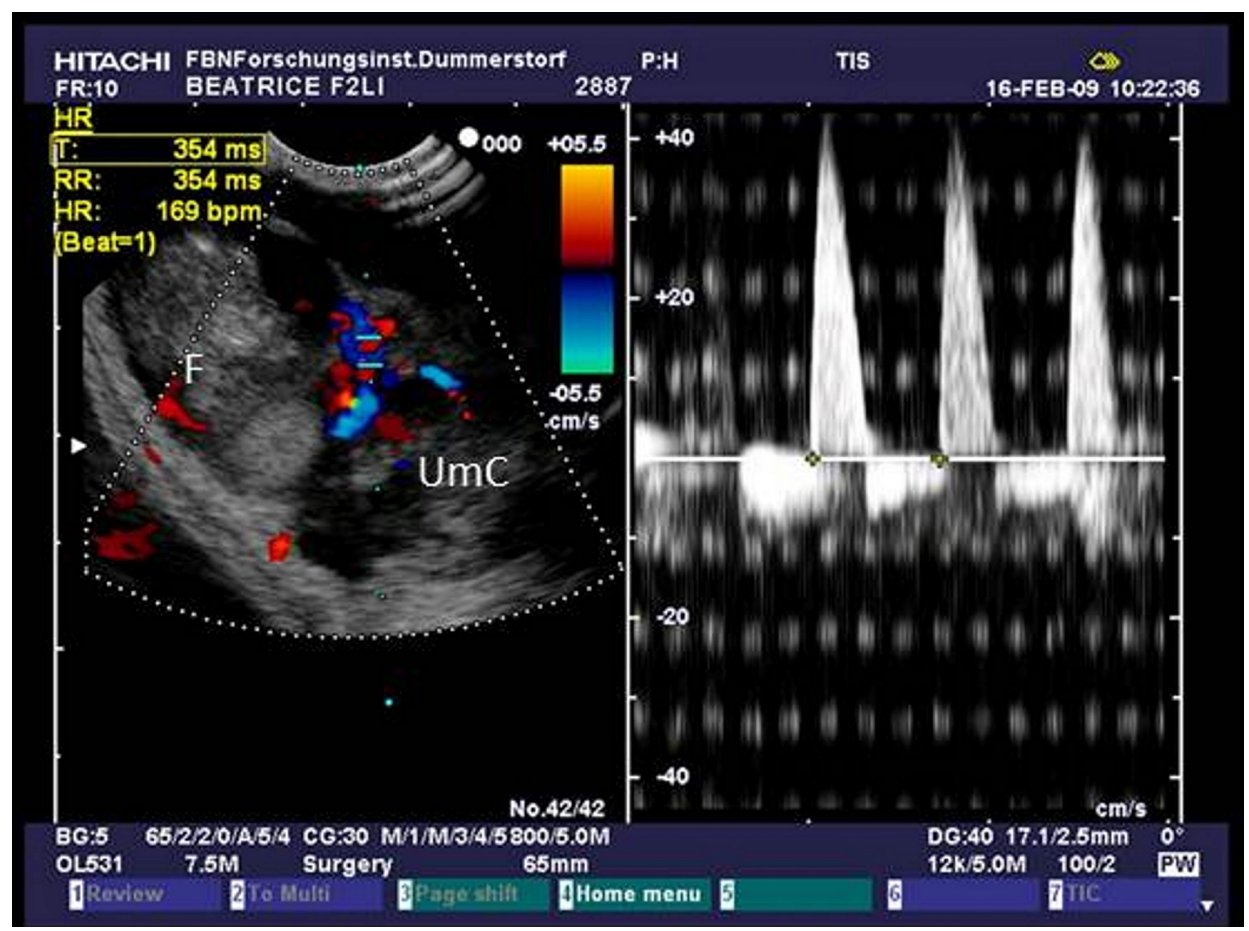

Fig 1. Doppler image and spectral mode of the umbilical cord (UmC) of a fetus (F) on PD 36.

Table 1. Fetal and umbilical blood flow parameters (LS means \pm SE) of fetuses on PD36, PD42 and PD51 ( $\mathrm{n}=26$ gilts)

\begin{tabular}{|c|c|c|c|c|c|}
\hline \multicolumn{2}{|l|}{ Parameter } & PD36 & PD42 & PD51 & $P$ value \\
\hline No. of fetuses & & 122 & 19 & 42 & - \\
\hline Fetus length & $(\mathrm{mm})$ & $31.3 \pm 0.8^{\mathrm{a}}$ & $45.3 \pm 1.9^{\mathrm{b}}$ & $54.2 \pm 1.4^{\mathrm{c}}$ & $\mathrm{P}<0.001$ \\
\hline Fetus area & $\left(\mathrm{cm}^{2}\right)$ & $3.55 \pm 0.20^{\mathrm{a}}$ & $6.22 \pm 0.49^{b}$ & $10.86 \pm 0.35^{\mathrm{c}}$ & $\mathrm{P}<0.001$ \\
\hline FHR ${ }^{1)}$ & (bpm) & $159 \pm 4^{\mathrm{d}}$ & $133 \pm 9^{\mathrm{e}}$ & $144 \pm 6$ & d,e $\mathrm{P}<0.05$ \\
\hline $\mathrm{T} 1^{2)}$ & $(\mathrm{ms})$ & $170.4 \pm 1.7$ & $172.4 \pm 4.3$ & $171.0 \pm 3.0$ & n.s. \\
\hline $\mathrm{T} 2^{3)}$ & (ms) & $209.5 \pm 11.6^{\mathrm{f,h}}$ & $278.9 \pm 27.6^{\mathrm{g}}$ & $265.4 \pm 19.7^{\mathrm{i}}$ & $\begin{array}{l}f, g \quad P=0.075 \\
h, i \mathrm{P}=0.059\end{array}$ \\
\hline $\mathrm{T} 2 / \mathrm{T} 1$ ratio & $(\%)$ & $124.1 \pm 6.5^{\mathrm{k}, \mathrm{m}}$ & $165.3 \pm 15.4^{1}$ & $154.1 \pm 11.1^{\mathrm{n}}$ & $\begin{array}{l}k, 1 \mathrm{P}=0.058 \\
{ }_{\mathrm{m}, \mathrm{n}} \mathrm{P}=0.072\end{array}$ \\
\hline PSV 4) & $(\mathrm{cm} / \mathrm{s})$ & $30.65 \pm 0.83$ & $31.92 \pm 1.99$ & $32.26 \pm 1.43$ & n.s. \\
\hline $\mathrm{TAV}^{5)}$ & $(\mathrm{cm} / \mathrm{s})$ & $17.54 \pm 0.36$ & $19.06 \pm 1.28$ & $18.71 \pm 0.90$ & n.s. \\
\hline $\mathrm{RI}^{6)}$ & & $0.95 \pm 0.01$ & $0.94 \pm 0.01$ & $0.94 \pm 0.01$ & n.s. \\
\hline PI 7 ) & & $1.68 \pm 0.01^{\mathrm{d}}$ & $1.59 \pm 0.02^{\mathrm{e}}$ & $1.69 \pm 0.02^{\mathrm{d}}$ & ${ }^{\mathrm{d}, \mathrm{e}} \mathrm{P}<0.05$ \\
\hline
\end{tabular}

Within row values with different superscripts differ. ${ }^{1)}$ Fetal heart rate, ${ }^{2)}$ Systolic pulse duration,

3) Interpulse duration, 4) Peak systolic velocity, 5) Time averaged velocity, 6) Resistance index,

7) Pulsatility index.

$(\mathrm{P}=0.08)$ to be higher on PD42 compared with PD36 and PD51.

To find possible differences in UmA blood flow parameters concerning fetal size, fetuses were retrospectively grouped as follows: small (lower 25\%), medium (mean 50\%) and large (upper 25\%), respectively. The results for each size class on PD36, PD42 and PD51 are shown in Table 2. Fetuses differed in size $(\mathrm{P}<0.001)$ within and between days of pregnancy. However, most of the recorded parameters, such as FHR, PSV, TAV, RI and PI did not differ among the size classes. Only systolic pulse duration tended to be higher $(\mathrm{P}=0.05)$ in large compared with small fetuses on PD36. Interpulse duration was lower in large fetuses on PD36 in comparison with PD51 $(\mathrm{P}<0.05)$.

Correlations were calculated between fetal size and UmA flow parameters; however, no significant results were obtained.

\section{Discussion}

Here, we report for the first time on respective Doppler indices in 
Table 2. Fetal and umbilical blood flow parameters (LS means \pm SE) of fetuses of different size classes, small (lower 25\%), medium (mean 50\%) and large (upper 25\%), on PD36, PD42 and PD51 ( $\mathrm{n}=26$ gilts)

\begin{tabular}{|c|c|c|c|c|c|c|c|c|c|c|}
\hline \multirow[t]{2}{*}{ Parameter } & \multicolumn{3}{|c|}{$\begin{array}{c}\text { PD36 } \\
\text { Fetal size }\end{array}$} & \multicolumn{3}{|c|}{$\begin{array}{c}\text { PD42 } \\
\text { Fetal size }\end{array}$} & \multicolumn{3}{|c|}{$\begin{array}{c}\text { PD51 } \\
\text { Fetal size }\end{array}$} & \multirow[t]{2}{*}{$P$ value } \\
\hline & Small & Medium & Large & Small & Medium & Large & Small & Medium & Large & \\
\hline No. of fetuses & 32 & 56 & 34 & 4 & 10 & 5 & 10 & 21 & 11 & \\
\hline Fetus area $\left(\mathrm{cm}^{2}\right)$ & $2.82 \pm 0.15^{\mathrm{a}, \mathrm{A}}$ & $3.69 \pm 0.12^{\mathrm{b}, \mathrm{A}}$ & $4.11 \pm 0.15^{\mathrm{b}, \mathrm{A}}$ & $4.31 \pm 0.41^{\mathrm{a}, \mathrm{B}}$ & $6.50 \pm 0.28^{\mathrm{b}, \mathrm{B}}$ & $7.28 \pm 0.39^{\mathrm{c}, \mathrm{B}}$ & $7.89 \pm 0.27^{\mathrm{a}, \mathrm{C}}$ & $10.96 \pm 0.20^{\mathrm{b}, \mathrm{C}}$ & $13.72 \pm 0.26^{\mathrm{c}, \mathrm{C}}$ & $\begin{array}{l}\mathrm{a}, \mathrm{b}, \mathrm{c} ; \mathrm{A}, \mathrm{B}, \mathrm{C} \\
\mathrm{P}<0.001\end{array}$ \\
\hline $\mathrm{FHR}^{1)}(\mathrm{bpm})$ & $154 \pm 5$ & $159 \pm 5$ & $162 \pm 5$ & $125 \pm 11$ & $133 \pm 10$ & $139 \pm 11$ & $145 \pm 8$ & $145 \pm 7$ & $141 \pm 8$ & n.s. \\
\hline $\mathrm{T} 1^{2)}(\mathrm{ms})$ & $164.6 \pm 3.0^{\mathrm{d}}$ & $169.6 \pm 2.3$ & $177.3 \pm 2.9^{\mathrm{e}}$ & $179.6 \pm 8.2$ & $167.9 \pm 5.4$ & $175.5 \pm 7.6$ & $172.9 \pm 5.3$ & $169.1 \pm 3.9$ & $171.7 \pm 5.1$ & $\begin{array}{c}\mathrm{d}, \mathrm{e} \\
\mathrm{P}=0.05\end{array}$ \\
\hline $\mathrm{T} 2^{3)}(\mathrm{ms})$ & $229.7 \pm 14.5$ & $207.0 \pm 13.0$ & $191.6 \pm 14.6^{\mathrm{f}}$ & $305.0 \pm 36.2$ & $273.7 \pm 30.4$ & $267.9 \pm 36.3$ & $253.6 \pm 25.6$ & $262.7 \pm 22.3$ & $284.9 \pm 24.5^{\mathrm{g}}$ & $\begin{array}{c}f, g \\
\mathrm{P}<0.05\end{array}$ \\
\hline $\mathrm{T} 2 / \mathrm{T} 1$ ratio $(\%)$ & $140.3 \pm 8.4^{\mathrm{h}}$ & $123.2 \pm 7.4$ & $108.0 \pm 8.5^{\mathrm{i}, \mathrm{k}}$ & $168.2 \pm 17.3$ & $168.2 \pm 21.3$ & $156.6 \pm 21.3$ & $148.0 \pm 15.0$ & $154.6 \pm 12.8$ & $161.2 \pm 14.3^{1}$ & $\mathrm{~h}, \mathrm{I} ; \mathrm{k}, \mathrm{l} \mathrm{P}<0.05$ \\
\hline $\mathrm{PSV}^{4)}(\mathrm{cm} / \mathrm{s})$ & $29.13 \pm 1.29$ & $31.18 \pm 1.03$ & $31.31 \pm 1.29$ & $34.41 \pm 3.45$ & $29.63 \pm 2.41$ & $34.64 \pm 3.29$ & $28.99 \pm 2.31$ & $32.88 \pm 1.77$ & $34.72 \pm 2.19$ & n.s. \\
\hline $\mathrm{TAV}^{5)}(\mathrm{cm} / \mathrm{s})$ & $16.85 \pm 0.64$ & $17.67 \pm 0.72$ & $18.04 \pm 0.91$ & $20.59 \pm 2.48$ & $17.74 \pm 1.67$ & $20.50 \pm 2.33$ & $17.74 \pm 1.63$ & $18.52 \pm 1.21$ & $19.93 \pm 1.55$ & n.s. \\
\hline $\mathrm{RI}^{6)}$ & $0.95 \pm 0.01$ & $0.95 \pm 0.01$ & $0.96 \pm 0.01$ & $0.97 \pm 0.02$ & $0.95 \pm 0.01$ & $0.92 \pm 0.02$ & $0.94 \pm 0.01$ & $0.95 \pm 0.01$ & $0.94 \pm 0.01$ & n.s. \\
\hline $\mathrm{PI}^{7)}$ & $1.66 \pm 0.03$ & $1.69 \pm 0.02$ & $1.68 \pm 0.03$ & $1.64 \pm 0.08$ & $1.57 \pm 0.05$ & $1.57 \pm 0.07$ & $1.66 \pm 0.05$ & $1.71 \pm 0.03$ & $1.66 \pm 0.05$ & n.s. \\
\hline
\end{tabular}

Values with different lower case superscripts differ significantly between fetal size classes, and values with different capital letters differ between PDs.

${ }^{1)}$ Fetal heart rate, ${ }^{2)}$ Systolic pulse duration, ${ }^{3)}$ Interpulse duration, ${ }^{4)}$ Peak systolic velocity, ${ }^{5)}$ Time averaged velocity, ${ }^{6}$ Resistance index, ${ }^{7)}$ Pulsatility index.

the pregnant pig at early and mid-gestation. The images obtained in our study by laparoscopic ultrasound scanning were mainly excellent due to the close proximity with the uterine surface. However, the laparoscopy ultrasound procedure revealed some difficulties that impede handling such as the restricted space in the abdomen and the high number and increasing size of fetuses. Furthermore, at PD36, fetuses are more or less 'free-floating' within the gestational sac. Nevertheless, representative data could be obtained from 183 fetuses. We aimed to analyze the total number of fetuses from one side. Collecting of data from $94 \%$ of the fetuses of the left uterine horn enabled us to demonstrate that it is possible to image systematically all fetuses from one side. Imaging the fetuses of both uterine horns requires prolonged anesthesia.

It should be considered that the flow data were obtained under general anesthesia (ketamine/azaperone). It is known that different anesthetic methods [28-30] and agents, e.g.,xylazine [31, 32], may influence uterine and fetal blood supply. However, ketamine does not seem to affect uterine blood flow [33,34], whereas azaperone can cause moderate hypotension and lowering of heart rate in pigs $[35,36]$.

Fetal size increased with ongoing gestation from PD36 to PD42 and PD51 by $45 \%$ and $73 \%$, respectively. Fetuses also varied in size on each PD. Grouping fetuses according to the lower and upper $25 \%$ revealed significant differences compared with the " $50 \%$ medium-size" group. The "lower 25\%" group can be considered as probably IUGR fetuses.

Umbilical flow data in the pig are not available. Therefore, we can only compare our data with those obtained in other domestic animals. The FHR was decreasing between PD36 and PD42 but did not decrease all the way to PD51. In goats, FHR decreased throughout gestation [23]. The FHR in the porcine fetuses was low, as found in goats during a comparable gestational period (150 vs. $240 \mathrm{bpm}$ ). The systolic peak and time averaged velocities did not change during the examined gestational period. In porcine fetuses, the PSV was two-times higher compared with that of rabbits [37] but half that of sheep fetuses [38]. Apparently, differences exist concerning species, the number of fetuses and the stage of gestation.

Volumetric blood flow assessment in small, convoluted umbilical arteries is difficult [38]. Therefore, qualitative analysis of blood flow velocity waveforms [16] or semiquantitative indexes, such as RI and PI, are often used. They are indexes for vascular resistance, and they are comparable within the same vessels and probably between breeds. In our study, the RI was not altered between PD36 to PD51 and ranged between 0.94 and 0.95 . Similarly high stable RIs were reported in comparable gestational periods for goats, rabbits and bitches [23, 37, 39]. As high RI is interpreted as high resistance and low perfusion and vice versa [40], reduced blood flow can be assumed.

The pulsatility index (PI) is regarded as an indicator of cardiac function and fetal jeopardy [41, 42]. In the present study, PI was decreasing from PD36 to PD42 and then increasing up to PD51, with values between 1.59 and 1.69. Also, in goats, a PI increase was observed [23], whereas in bitches, PI decreased prior to whelping [39]. The presence of elevated RI and PI could be interpreted as high blood flow resistance in the placenta, perhaps due to intrauterine growth restriction [43]. Furthermore, abnormal placentation and trophoblastic invasion may result in abnormal waveform patterns of the UmA in humans [44]. However, in our study, after grouping the fetuses according to small, medium and large sizes no differences were obtained both for RI and PI on all examined days of gestation. In human fetuses, a tendency for a lower RI in large fetuses with ongoing pregnancy was reported [45]. Furthermore, other measured parameters (FHR, PSV) were not linked to fetal size. One exception was the systolic pulse duration $\mathrm{T} 1$ between small and large fetuses on PD36. However, such differences were not observed on other PDs, and this finding should not be overestimated due to the significance level of $\mathrm{P}=0.05$. We did not find any predominant parameter that could describe the umbilical blood flow in porcine fetuses and particularly in IUGR fetuses.

In conclusion, laparoscopy guided ultrasound measurement is a suitable method to evaluate fetal blood flow in pigs. Our study 
obtained, for the first time, Doppler flow indices of umbilical arteries in the porcine fetus during early-mid gestation. We did not find any relation between fetal blood flow indices and fetal growth (IUGR). However, with further studies based on these flow indices, it may be possible to evaluate nutrient- or stress-related influences on fetal growth and development, particularly in the case of IUGR.

\section{Acknowledgments}

The authors are grateful to Ms V Tesch and Dr G Stürmer for technical assistance and for care and handling of the animals.

\section{References}

1. Brüssow K-P, Wähner M. Biological potential of fecundity of sows. Züchtungskunde 2008; 80: 370-377.

2. Wu G, Bazer FW, Wallace JM, Spencer TE. Intrauterine growth retardation: implications for the animal sciences. J Anim Sci 2006; 84: 2316-2337. [Medline]

3. Litten JC, Drury PC, Corson AM, Lean IJ, Clarke L. The influence of piglet birth weight on physical and behavioural development in early life. Biol Neonate 2003; 84: 311-318. [Medline] [CrossRef]

4. Rehfeldt C, Kuhn G. Consequences of birth weight for postnatal growth performance and carcass quality in pigs as related to myogenesis. J Anim Sci 2006; 84(Suppl): E113-E123. [Medline]

5. Reynolds LP, Redmer DA. Utero-placental vascular development and placental function. J Anim Sci 1995; 73: 1839-1851. [Medline]

6. Reynolds LP, Ford SP, Ferell LC. Blood flow and steroid uptake of the gravid uterus and fetus of sows. J Anim Sci 1985; 61: 968-974. [Medline]

7. Molina JR, Musah AI, Hard DL, Anderson LL. Conceptus development after vascular occlusion of the middle artery in the pig. J Reprod Fertil 1985; 75: 501-506. [Medline] [CrossRef]

8. Ashworth CJ, Finch AM, Page KR, Nwagu MO, McArdle HJ. Causes and consequences of fetal growth retardation in pigs. Reproduction 2001; 58(Suppl): 233-246. [Medline]

9. Ford SP, Christenson RK. Blood flow to uteri of sows during the estrous cycle and early pregnancy: local effect of the conceptus on the uterine blood supply. Biol Reprod 1979; 21: 617-624. [Medline] [CrossRef]

10. Père MC, Etienne M. Uterine blood flow in sows: effects of pregnancy stage and litter size. Reprod Nutr Dev 2000; 40: 369-382. [Medline] [CrossRef]

11. Campbell S, Bewley S, Cohen-Overbeek T. Investigation of the uteroplacental circulation by Doppler ultrasound. Semin Perinatol 1987; 11: 362-368. [Medline]

12. Gudmudsson S, Marsal K. Umbilical and uteroplacental blood flow velocity waveforms in pregnancies with fetal growth retardation. Eur J ObstetGynecolReprodBiol 1988; 27: 187-196.

13. Dickey RP. Doppler ultrasound investigation of uterine and ovarian blood flow in infertility and early pregnancy. Hum Reprod Update 1997; 3: 467-503. [Medline] [CrossRef]

14. Detti L, Akiyama M, Mari G. Doppler blood flow in obstetrics. Curr Opin Obstet Gynecol 2002; 14: 587-593. [Medline]

15. Giacobbe M, Zeferino LC, Franzin CM, Faundes A. Uteroplacental circulation during the first trimester of normal and abnormal pregnancy. Reprod Biomed Online 2002; 4: 62-67. [Medline] [CrossRef]

16. Laurin J, Marsal K, Persson PH, Lingman G. Ultrasound measurement of fetal blood flow in predicting outcome. Br J Obstet Gynaecol 1987; 94: 940-948. [Medline] [CrossRef]

17. Di Naro E, Raio L, Ghezzi F, Franchi M, Romano F, Addario VD. Longitudinal umbilical vein blood flow changes in normal and growth-retarded fetuses. Acta $\mathrm{Ob}$ stet Gynecol Scand 2002; 81: 527-533. [Medline]

18. Bollwein H, Baumgartner U, Stolla R. Transrectal Doppler sonography of the uterine blood flow in cows during pregnancy. Theriogenology 2002; 57: 2053-2061. [Medline] [CrossRef]

19. Bollwein H, Weber F, Woschee I, Stolla R. Transrectal Doppler sonography of uterine and umbilical blood flow during pregnancy in mares. Theriogenology 2004; 61: 499-509. [Medline] [CrossRef]

20. Muijsers GJ, Hasaart TH, Ruissen CJ, van Huisseling H, Peeters L, de Haan J. The respons of the umbilical and femoral artery pulsatility indices in fetal sheep to progressively reduced uteroplacental blood flow. J Dev Physiol 1990; 13: 215-221.
[Medline]

21. Hüneke B, Schröder HJ. Doppler ultrasound studies of fetal blood flow in the animal experiment. Gynakologe 1992; 25: 341-351. [Medline]

22. Tchirikov M, Hecher K, Deprest J, Zikuling L, Devlieger R, Schröder HJ. Doppler ultrasound measurements in the central circulation of anesthetized fetal sheep during obstruction of umbilical-placental blood flow. Ultrasound ObstetGynecol 2001; 18: 656-661. [CrossRef]

23. Serin G, Gökdal O, Tarimcilar T, Atay $\mathbf{O}$. Umbilical artery Doppler sonography in Saanen goat fetuses during singleton and multiple pregnancies. Theriogenology 2010; 74: 1082-1087. [Medline] [CrossRef]

24. Brüssow K-P, Rátky J, Kanitz W, Becker F. Determination of the duration of ovulation in gilts by means of laparoscopy. ReprodDomestAnim 1990; 25: 184-190.

25. Kurmanavichius J, Baumann H, Huch R, Huch A. Determination of the minimum number of cardiac cycles necessary to ensure representative blood flow velocity measurements. J Perinat Med 1989; 17: 33-39. [Medline] [CrossRef]

26. SAS Institute Inc. Base SAS $® 9.2$ Procedures Guide2009. Cary, NC

27. SAS Institute Inc. SAS/STAT ${ }^{8} 9.2$ User's Guide, Second Edition 2009. Cary, NC.

28. Manaa EM, Romeih MS. Fetal response to epidural analgesia as evidenced by Doppler indices. Middle Eas J Anesthesiol 2008; 19: 1321-1336.

29. Okutomi T, Whittington RA, Stein DJ, Morishima HO. Comparison of the effect of sevoflurane and isoflurane anesthesia on the maternal-fetal unit in sheep. $J$ Anesth 2009; 23: 392-398. [Medline] [CrossRef]

30. Fratelli N, Prefumo F, Andrico S, Lorandi A, Recupero D, Tomasoni G, Frusca T. Effects of epidural analgesia on uterine artery Doppler in labour. Br J Anaesth 2011; 106: 221-224. [Medline] [CrossRef]

31. Weiner CP, Herring J, Wang J, Wang L, Farley D, Van Orden D, Chestnut D. Chronic measurement, using a Doppler probe, on uterine artery flow in the gravid guinea-pig. J Reprod Fertil 1986; 77: 247-256. [Medline] [CrossRef]

32. Sakamoto H, Misumi K, Nakama M, Aoki Y. The effect of xylazine on uterine pressure, uterine blood flow, materna and fetal cardiovascular and pulmonary function in pregnant goats. J Vet Med Sci 1996; 58: 211-217. [Medline] [CrossRef]

33. Craft JB, Coaldrake LA, Yonekura ML, Dao SD, Co EG, Roizen MF, Mazel P, Gilman R, Shokes L, Trevor AJ. Ketamine, cathecholamine, and uterine tone in pregnant ewes. Am J Obstet Gynecol 1983; 146: 429-434.

34. Strümper D, Gogarten W, Durieux ME, Hartleb K, Van Aken H, Marcus MA. The effect of S+-ketamin and racemic ketamine on uterine blood flow in chronically instrumented pregnant sheep. AnesthAnalg 2004; 98: 497-502.

35. Gregory NG, Wilkins LJ. Effect of azaperone on cardiovascular responsiveness in stress-sensitive pigs. J Vet Pharmacol Ther 1986; 9: 164-170. [Medline] [CrossRef]

36. van Woerkens LJ, Duncker DJ, Huigen RJ, van der Giessen WJ, Verdouw PD. Redistribution of cardiac output caused by opening of arteriovenous anastomoses by a combination of azaperone and metomidate. Br J Anaesth 1990; 65: 393-399. [Medline] [CrossRef]

37. Polisca A, Scotti L, Orlandi R, Brecchia G, Boiti C. Doppler evaluation of maternal and fetal vessels during normal gestation in rabbits. Theriogenology 2010; 73 358-366. [Medline] [CrossRef]

38. Acharya G, Erkinaro T, Makikallio K, Lappalainen T, Rasanen J. Relationship among Doppler-derived umbilical artery absolute velocities, cardiac function, and placental volume blood flow and resistance in fetal sheep. Am J Physiol Heart Circ Physiol 2004; 286: H1266-H1272. [Medline] [CrossRef]

39. Miranda SA, Domingues SF. Conceptus ecobiometry and triplex Doppler ultrasonography of uterine and umbilical arteries for assessment of fetal viability in dogs. Theriogenology 2010; 74: 608-617. [Medline] [CrossRef]

40. Bollwein H, Kolberg B, Stolla R. The effect of exogenous estradiol benzoate and altrenogest on uterine and ovarian blood flow during the estrous cycle in mares. Theriogenology 2004; 61: 1137-1146. [Medline] [CrossRef]

41. Kiserud T, Eik-Nes SH, Blaas HG, Hellevik LR, Simensen B. Ductusvenosus velocity and the umbilical circulation in the serious growth-retarded fetus. Ultrasound ObstetGynecol 1994; 4: 109-114. [CrossRef]

42. Hecher K, Campbell S. Characteristics of fetal venous blood flow under normal circumstances and during fetal disease. Ultrasound ObstetGynecol 1996; 7: 68-83. [Medline] [CrossRef]

43. Seyam YS, Al-Mahmeid MS, Al-Tamimi HK. Umbilical arteryDoppler flow velocimetry in intrauterine growth restriction and itsrelation to perinatal outcome. Int $J$ Gynecol Obstet 2002; 77: 131-137. [CrossRef]

44. Baschat AA. Integrated fetal testing in growth restriction: combiningmultivessel Doppler and biophysical parameters. Ultrasound Obstet Gynecol 2003; 21: 1-8. [CrossRef]

45. Burkhardt T. Comparison of umbilical resistance index of monochorial and dichorial twin pregnancy. PhD Thesis 2003; Faculty of Medicine Charité, Humboldt University Berlin. 